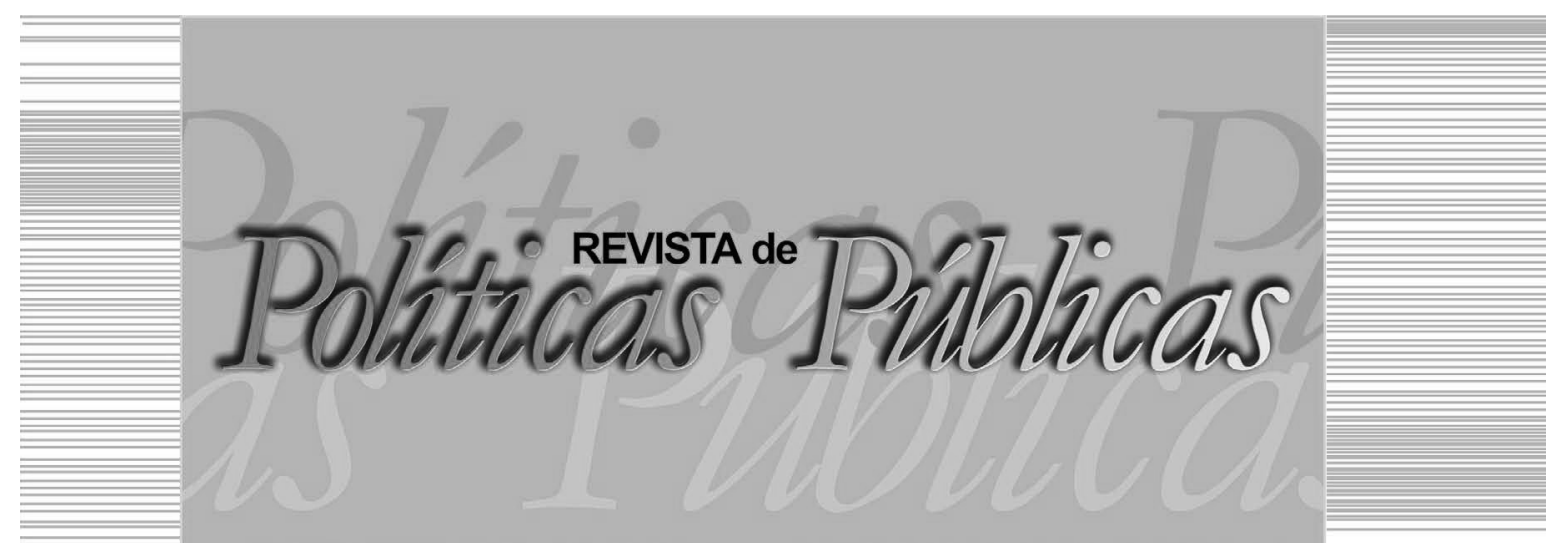

\title{
CRISE ECONÔMICA E INSTABILIDADE \\ POLITICA: cenários da ofensiva do capital contra o trabalho no Brasil
}

\section{Eduardo Perondi ${ }^{l}$}

\section{Resumo}

Este artigo analisa as principais características das mudanças na legislação do trabalho que estão sendo efetivadas no Brasil. Tem-se como premissa o entendimento de que essa agenda é parte de uma ofensiva capitalista que visa rebaixar o valor da força de trabalho e aumentar as margens de lucro. A hipótese apresentada aqui é a de que o avanço desse tipo de medida é facilitado pelo contexto de instabilidade que vive o país, devido aos efeitos da recente crise econômica mundial. Por essa razão, no texto são apresentados argumentos que expõem os efeitos dessa crise e as mudanças de política econômica realizadas pelos governos brasileiros, assim como discute os efeitos da agenda de austeridade para o aumento da ingovernabilidade no período recente.

Palavras-chave: Crise econômica, ofensiva capitalista, reforma trabalhista.

\section{ECONOMIC CRISIS AND POLITICAL INSTABILITY:}

context of the capital offensive against the labor in Brazil

\begin{abstract}
This article analyzes the main characteristics of the changes in labor legislation that are currently being implemented in Brazil. It starts from the understanding that this agenda is part of a capitalist offensive that aims to reduce the value of the workforce and increase profit margins. The hypothesis presented here is that

1 Graduado em Ciências Sociais, Doutorando em Estudos Latinoamericanos pela Universidad Nacional Autónoma de México (UNAM). E-mail: eduperondi@gmail. com / Universidad Nacional Autónoma de México - UNAM: Av. Universidad 3000, Cd. Universitaria, Coyoacán 04510, Ciudad de México, D.F. México.
\end{abstract}


the progress of this type of measure is facilitated by the context of instability that the country is experiencing due to the effects of the recent global economic crisis. For this reason, the text presents arguments that expose the effects of this crisis and the changes of economic policy carried out by the Brazilian governments, as well as discusses the effects of the austerity agenda for increasing ungovernability in the recent period.

Key words: economic crisis, capitalist offensive, labor reform.

\section{INTRODUÇÃO}

Recentemente foi aprovada uma profunda reforma trabalhista no Brasil, que pode ser descrita como o maior retrocesso desde que foi criada a legislação do trabalho no país. Antes dela já havia sido aprovada uma lei que permite a generalização da terceirização, inclusive nas atividades-fim das empresas. Outras propostas de caráter similar seguem tramitando, como as mudanças na Previdência e no trabalho rural. Somadas, configuram uma agenda regressiva para os trabalhadores, organizada desde distintas frentes do Estado.

Essa agenda representa os interesses do empresariado e dos capitais investidos no Brasil, que pretendem rebaixar o valor da força de trabalho, aumentando consequentemente a margem de lucro dos negócios. No entanto, trata-se de um projeto do capital que ocorre em todo o mundo desde a década de 1970, e ganhou novo impulso a partir da eclosão da crise mundial de 2008.

Compreende-se que é parte de uma nova ofensiva do capital, à qual é fundamental entender as razões e características, assim como relacioná-la com o momento em que ocorre. Afinal, vem de longa data a propalada necessidade de modernizar as relações de trabalho, permitir a prevalência do negociado sobre o legislado ou acabar com o déficit da previdência. Inclusive várias mudanças nas relações de trabalho já haviam sido feitas com esse caráter em governos anteriores - apesar de que nenhuma com a abrangência dessa última. Mas por que razão essa agenda agora vem sendo possível? O cenário de crise econômica e instabilidade política interfere de que maneira nesse contexto?

Para lançar alguns argumentos a essa discussão, o presente texto situa os efeitos da última crise mundial sobre a economia brasileira, destacando as mudanças e continuidades de política econômica. Em seguida, discute-se como os efeitos da crise e das políticas de austeridade contribuíram para o aumento da ingovernabilidade, 
e como esse cenário foi aproveitado para aprofundar a ofensiva do capital contra o trabalho. Por fim, são apresentadas as características principais das mudanças na legislação do trabalho, objetivo principal dessa agenda.

\section{A CRISE E AS MUDANÇAS DE POLÍTICA ECONÔMICA}

Durante boa parte da primeira década do século XXI a economia brasileira alcançou significativos índices de crescimento, bastante superior ao verificado na década de 1990. Esse bom desempenho sustentou o otimismo entre setores do empresariado e do governo, muitos dos quais acreditavam que o Brasil caminhava para se tornar uma nova potência global. No entanto, essas manifestações eufóricas ocultavam ou menosprezavam as bases reais em que se assentava esse êxito brasileiro.

Em primeiro lugar, é necessário destacar que o crescimento econômico na década de 2000 foi favorecido por um contexto favorável da economia mundial, com maior liquidez de capital e preços altos das commodities (petróleo, matérias-primas e alimentos). Isso levou o Brasil a aumentar a produção de produtos primários e aprofundar o padrão de reprodução do capital ${ }^{1}$ baseado na exportação de soja, minério de ferro, petróleo, café, açúcar, carnes, milho, diminuindo a participação de produtos com maior valor agregado. É significativo que entre 2005-2011 a participação dos produtos manufaturados nas exportaç̃oes brasileiras tenha caído de $55 \%$ para $36 \%$ do total. (FUNDAÇÂO CENTRO DE EESTUDOS COMÉRCIO EXTERIOR, 2012).

Em segundo lugar, a política econômica aplicada pelos governos do Partido dos Trabalhadores (PT) manteve, em geral, as bases neoliberais estabelecidas com o Plano Real, especialmente o chamado tripé macroeconômico: superávit primário, controle do câmbio e metas de inflação determinadas por elevadas taxas de juros. Isso permitiu lucros sem precedentes ao sistema financeiro, e drenou parte importante do orçamento do Estado para serviços da dívida pública.

No entanto, o cenário favorável permitiu que mesmo com tal política econômica a arrecadação do governo federal aumentasse significativamente, proporcionando recursos que seriam utilizados em diferentes áreas: para aumentar a taxa de investimentos estatal 
na economia; dar apoio à expansão e internacionalização de grandes grupos econômicos nacionais; promover uma oferta maior do crédito ao consumo por parte dos bancos estatais; além de um incremento substancial em iniciativas de distribuição de renda direcionadas ao combate da pobreza extrema - especialmente o Programa Bolsa Família.

A crise econômica que eclodiu entre 2007-08 e inicialmente com mais força nas economias desenvolvidas (Estados Unidos e União Europeia), teve impacto no Brasil em 2009, interrompendo o ciclo de crescimento. $\mathrm{O}$ governo brasileiro reagiu com uma série de medidas contracíclicas que tiveram êxito em reverter a diminuição de $0,3 \%$ do Produto Interno Brasileiro (PIB) em 2009 para um surpreendente aumento de 7,5\% em 2010. A rápida recuperação levou Lula a afirmar que a crise era uma marolinha, enquanto Dirceu (2011) afirmava que o Brasil havia sido o último país a entrar e o primeiro a sair da crise mundial.

No entanto, a desaceleração econômica que se verificaria a partir de 2012 até se transformar em recessão em 2015, iria mostrar o momento exato em que a crise chegaria no Brasil. A queda no preço das commodities e a desaceleração da demanda chinesa foram importantes fatores para a perda do dinamismo da economia.

De acordo com Coggiola (2016), a crise trouxe consigo o retorno da luta de classes, pois sob o argumento da austeridade se aplicou no final de 2010 um ajuste fiscal com redução do crédito, aumento das taxas de juros, corte de investimentos e gastos públicos (sobretudo em educação e saúde), congelamento do salário dos funcionários públicos, deflagrando importantes greves na construção civil, educação básica e superior, refinarias, petroquímica, hidrelétricas, além de protestos contra as tarifas do transporte. (COGGIOLA, 2016).

O impacto do ajuste resultou numa diminuição de grande magnitude da atividade econômica, onde o PIB que cresceu 2,7\% em 2011 passou para apenas 0,9\% em 2012. De acordo com Barbosa (2013), o efeito da política econômica restritiva aplicada pelo governo Dilma foi maior inclusive do que o esperado pelo governo.

Ao perceber a gravidade e a extensão da desaceleração, o governo Dilma decidiu outra vez mudar a política econômica no início de 2012. A ideia era repetir a fórmula de políticas anticíclicas 
aplicadas por Lula em 2008-09, e retomar o modelo chamado de neodesenvolvimentista. Singer (2015) lembra que a iniciativa foi batizada de nova matriz econômica e também de ensaio desenvolvimentista.

As principais medidas aplicadas consistiam em: 1) redução da taxa de juros; 2) aumento do crédito subsidiado a empresas via bancos públicos; 3) redução de impostos sobre produtos industrializados (automóveis, eletrodomésticos, eletrônicos); 4) isenção de impostos (entre eles a contribuição patronal à Previdência) para 42 setores da economia; 5) pacote de concessões de estradas e ferrovias à iniciativa privada; 6) redução do preço da eletricidade; 7) desvalorização da moeda; 8) controle dos fluxos de capital externo (para impedir a valorização cambial; 9) aumento de impostos a produtos industrializados e prioridade para o conteúdo nacional nas compras do governo. (SINGER, 2015).

A iniciativa estava direcionada principalmente a salvar os lucros industriais dos efeitos da crise. E o fazia com a diminuição dos custos trabalhistas e transferências diretas e indiretas de recursos do Estado para fomentar os lucros dos capitais internacionais e promover a internacionalização de setores da burguesia interna.

Mas atender às reivindicações do setor industrial não é a mesma coisa que adotar uma política industrial. E ainda que se destaquem os aspectos positivos dessa iniciativa, se faz necessário problematizar que possibilidade tinha o Brasil nesse momento de criar uma política de desenvolvimento industrial, submetido como estava a um padrão de reprodução do capital baseado cada vez mais em produtos primários. A esperança (neo) desenvolvimentista, ou a possibilidade histórica de mudar o caráter da economia dependente através de políticas econômicas sem nenhum processo de ruptura com os interesses hegemônicos, já havia sido descartada em seu momento por importantes intelectuais como Florestan Fernandes (1987) e Ruy Mauro Marini (1981).

Os únicos momentos em que se tentou flexibilizar o caráter monetarista da política econômica neoliberal foi quando a crise mundial impactou com mais força a economia brasileira (2008 e 2012), e mencionadas políticas foram revertidas e substituídas por ajustes fiscais austeros logo que se manifestou o descontentamento do capital financeiro (os governos petistas aplicaram ajustes fiscais em 2003, 2011 e 2015). 
De fato, esse foi o desfecho do ensaio desenvolvimentista de Dilma a partir de 2013. A deterioração dos indicadores econômicos corroeu as bases de apoio do governo também entre as frações burguesas que haviam sido beneficiadas durante o ciclo petista. A única fidelidade desses setores é com seus lucros.

Apesar de todos os benefícios fiscais e isenções direcionados ao setor, a Confederação Nacional da Indústria (CNI, 2013) lamentava a perda de rentabilidade dos projetos e exigia medidas para reduzir os custos de produção e aumentar a produtividade, reclamando do ritmo lento e incompleto das iniciativas do governo nesse âmbito.

Nesse mesmo ano, segundo Braga (2016), os trabalhadores protagonizaram uma onda grevista inédita na história do país, somando 2.050 greves, inclusive em categorias profissionais sem grande tradição de mobilização, como os trabalhadores mais precarizados do setor de serviços privados.

Além das greves, 2013 foi palco das Jornadas de Junho, onde grandes massas saíram às ruas do país para protestar contra a repressão pelo aumento das tarifas do transporte e para denunciar as prioridades do Estado, que destinava grandes somas à construção de estádios para a copa do mundo e cortava orçamento da saúde e educação. As Jornadas são um evento importante para compreender a mudança de estratégia na luta de classes, pois a explosão social levou as classes dominantes a alterarem sua estratégia, passando da repressão à disputa política, em face da insatisfação que aumentava.

\section{AUMENTO DA INGOVERNABILIDADE E AJUSTE FISCAL}

A burguesia conseguiu dar um conteúdo conservador a esse descontentamento social, sobretudo com o tema do combate à corrupção. A tática era ocupar o debate político com a investigação da Lava Jato, que trata as corruptas relações entre empresas privadas e financiamento eleitoral. No entanto, isso contribuiu também para aumentar a instabilidade política, expondo as engrenagens do sistema e envolvendo setores importantes do empresariado e da classe política nas denúncias.

A eleição presidencial de 2014 evidenciou as rupturas no bloco burguês que antes apoiava a continuidade do PT, resultando numa vitória apertada de Dilma Rousseff (PT) no segundo turno, 
CRISE ECONÔMICA E INSTABILIDADE POLÍTICA:

cenários da ofensiva do capital contra o trabalho no Brasil

sobre Aécio Neves, Partido da Social Democracia Brasileira (PSDB). Foram fundamentais para o resultado as promessas de Dilma de que não iria retirar direitos dos trabalhadores e de que não faria um ajuste fiscal tal como seus adversários admitiam. No entanto, ainda durante a disputa, (mesmo) demitiu Guido Mantega, Ministro da Fazenda responsável pela nova matriz econômica, em um claro gesto aos mercados de que faria um novo governo em seu segundo mandato.

O ano de 2015 iniciou com a política econômica ortodoxa de Joaquim Levy, alto funcionário do banco Bradesco escalado para o lugar de Mantega. Este logo lançou um profundo ajuste fiscal, limitando direitos trabalhistas e cortando gastos correntes do orçamento público.

O corte orçamentário alcançou, de acordo com Fattorelli (2015), a soma de 80 bilhões de reais em 2015, afetando, sobretudo, as pastas responsáveis por serviços públicos: o Ministério das Cidades perdeu $54 \%$ do seu orçamento, a Saúde $42 \%$ e a Educação $23,7 \%$. Como consequência, além da inevitável perda de qualidade na oferta dos serviços, houve muitas greves das categorias nesses setores, que, entretanto, em geral, eram ignoradas e combatidas pelo governo. Restrito aos chamados gastos correntes do governo, o corte não atingiu os gastos financeiros - que somam mais de $44 \%$ do total das despesas.

Quanto à restrição de direitos trabalhistas, as medidas consistiam em dificultar o acesso a direitos laborais fundamentais para os trabalhadores mais precarizados, como o seguro desemprego, abono salarial, pensão por morte e auxílio para trabalhadores doentes. Foram estipuladas regras e tempos de trabalho mais longos para a acessão aos benefícios. Os gastos com seguro desemprego durante o ano de 2015, por exemplo, foram reduzidos apesar do aumento significativo das demissões nesse ano. (GASTO..., 2015).

As promessas não cumpridas de Dilma agradaram ao capital financeiro, mas não foram suficientes para acalmar a todos os setores burgueses. A profundidade da crise já apresentava um custo alto para a economia, especialmente para os setores empresariais pequenos e médios. Isso porque a política de austeridade estrangulava a economia e aprofundava a crise, transformando-a em recessão. 
A ingovernabilidade se manifestava cada vez com mais força, resultado da crise econômica e também consequência da política de ajuste fiscal. Enquanto Aécio Neves encabeçava o movimento dos derrotados na eleição de 2014 para derrubar Dilma, importantes setores dominantes eram mais cautelosos: as Federações Industriais de São Paulo (FIESP) e Rio de Janeiro (FIRJAN), grandes bancos como Itaú e Bradesco, monopólios de comunicação como as Organizações Globo, todos se manifestaram em defesa da governabilidade e da permanência de Dilma até o final de 2015. Entidades das igrejas católicas e evangélicas criticavam a possiblidade de impeachment. Porta-vozes dos grandes capitais estrangeiros como Financial Times e New York Times também afirmavam que Dilma deveria permanecer no cargo.

Por outro lado, o avanço das investigações da Lava Jato envolvia cada vez mais personagens políticos importantes, como os Presidentes da Câmara de Deputados Eduardo Cunha e do Senado Renan Calheiros, ambos do Partido do Movimento Democrático Brasileiro (PMDB). Romero Jucá, senador e um dos articuladores desse partido, comentava a necessidade de mudar o governo para estancar a sangria das investigações. (VALENTE, 2016).

Além disso, a devastação social resultante da crise se aprofundava: aumento do desemprego, inflação alta e diminuição do consumo, precariedade na atenção aos serviços públicos fundamentais como saúde, educação, transporte, moradia. Movimentos sociais e sindicatos intensificaram a crítica ao ajuste, pressionando parlamentares do PT e de partidos da base aliada do governo a criticar a política de austeridade.

O fato é que o governo de Dilma, ao assumir uma política de austeridade, corroía cada vez mais os laços já desgastados com suas bases sociais e eleitorais provocando, assim, rupturas na base do governo e no interior do partido. Por outro lado, as classes dominantes cobravam determinação e coesão do PT e do governo para aplicar tal política. Essa dupla pressão fracionava a tática de conciliação que havia caracterizado a gestão petista. Para o capital, o que o momento exigia era um governo convencido em atacar o mundo do trabalho para beneficiar as frações burguesas ante os efeitos da crise.

\section{APROFUNDAMENTO DA CRISE E DA OFENSIVA DO CAPITAL}


A ofensiva do capital não tem como objetivo criar instabilidade e derrubar governos, ainda que os momentos de incerteza possam ser favoráveis para o avanço de seus objetivos - principalmente aumentar a liberalização da economia para a entrada de investimentos de capital estrangeiro. A instabilidade política é parte das consequências que o avanço desse processo gera.

De acordo com Harvey (2011), desde a década de 1980 começou a dificuldade do capital para encontrar formas adequadas de valorização, gerando recorrentes crises de superacumulação. Os momentos de crise são também oportunidades, representam os racionalizadores irracionais do capitalismo, onde os desequilíbrios e as contradições (poder) podem ser temporariamente resolvidos.

As crises periódicas são, portanto, eventos recorrentes na economia capitalista, que alterna períodos de expansão com períodos de recessão. Essa parece ser uma explicação coerente para o que aconteceu com o Brasil a partir de 2011-12. Por essa razão, descrever a crise como uma estratégia golpista da direita para tirar o PT do governo, como propõe Sader (2016), parece reduzir o problema a alguma das suas consequências.

No Brasil, a ofensiva se materializou com a pressão para adotar um ajuste fiscal de caráter ortodoxo e pela realização de contrarreformas destinadas a retirar direitos trabalhistas e eliminar políticas sociais. Essa agenda está sintetizada no documento Ponte para o futuro, apresentado pelo PMDB de Temer, quando esse ainda não havia rompido sua relação com Dilma.

O conteúdo da proposta pode ser dividido em cinco eixos fundamentais: 1) ajuste fiscal para frear o crescimento da dívida pública e da inflação; 2) redução dos custos trabalhistas e aumento da produtividade do trabalho, através do aumento da flexibilidade nas contratações/demissões, generalização da terceirização, incremento tecnológico; 3) redução do fundo social, eliminando obrigações orçamentarias a políticas sociais e desindexação dos benefícios da reforma da Previdência; 4) favorecer novos negócios e investimentos, através de privatizações e concessões (pré-sal, portos, aeroportos, rodovias, companhias de energia e saneamento, entre outros); 5) maior abertura comercial e busca de acordos preferencialmente com Estados Unidos e União Europeia em detrimento do Mercosul. 
A realização de alguns desses compromissos foi assumido ainda durante o governo de Dilma, e as dificuldades do governo em aplicá-las também é um fator importante para compreender a sua deposição. O próprio Temer admitiu, depois, que a dificuldade ou a resistência do governo Dilma em aplicar essa agenda era a causa do impeachment (FERNANDES, 2016), deixando de lado o pretexto usado das pedaladas fiscais.

Os resultados dessa investida não tardaram em aparecer. A recessão económica e a desvalorização da moeda abarataram os ativos brasileiros para os investidores estrangeiros. No Fórum Econômico Mundial de Davos (Suíça) se exaltava que o Brasil estava pela metade do preço. (MOREIRA, 2016).

Uma economia em profunda recessão, cuja produção industrial alcançava 33 meses seguidos de queda, mas onde o Investimento Externo Direto (IED) atingia volumes bastante altos (U\$D 64 bilhões em 2015), relativamente superior ao observado na China e na Índia, só pode significar que essa economia oferece boas condições de valorização aos capitais. (MARTINS, 2017).

A concentração e centralização dos capitais encontra na crise económica o momento favorável para aprofundar-se, afetando os grandes grupos privados nacionais - se estima que a metade deles já se desfez de parte de seus negócios. (WIZIAK, 2016). Setores como a construção civil e frigoríficos, protegidos e apoiados pelo Estado brasileiro frente à competição externa, podem resultar bastante afetados pela abertura em curso.

A aprovação da mudança do modelo de exportação do petróleo do pré-sal, a privatização de companhias de eletricidade, águas e saneamento, bancos, aeroportos, rodovias, entre outros, demonstram que tudo que sobrou nas mãos do Estado é objeto de cobiça dos fluxos de capital. Está em discussão nova (des)regulação para a mineração e o fim das restrições à compra de terras por estrangeiros, sem falar na desconsideração das demarcações de terras indígenas e quilombolas. Tudo busca favorecer os fluxos de capital em busca de valorização.

Outra parte dos resultados já alcançados pela atual ofensiva capitalista no Brasil é o deterioro das condições de vida da classe trabalhadora. A taxa oficial de desemprego dobrou entre 2014 e 2016, segundo o Instituto Brasileiro de Geografia e Estatística (IBGE, 
2017), afetando a mais de 14 milhões de trabalhadores. Devemos somar a essa conta também outros 23 milhões de subocupados, considerando que os ganhos médios dos trabalhadores também foram reduzidos; nas negociações salariais (para as categorias que têm acordo coletivo) segundo o Departamento Intersindical de Estatística e Estudos Socioeconômicos (DIEESE, 2016), 39\% delas teve reajuste abaixo da inflação anual, sem falar que muitos reajustes foram parcelados. Outro dado importante é que as novas contratações pagam salários $21 \%$ mais baixos do que os recebidos pelos demitidos na mesma ocupação. (CARNEIRO, 2017).

O rebaixamento salarial e o incremento do exército de reserva já são um feito da crise no Brasil. Como se não bastasse, o governo Temer aprovou congelar os gastos sociais por um período de 20 anos, afetando o chamado salário indireto dos trabalhadores. $\mathrm{O}$ empobrecimento e o aumento da miséria da população brasileira é um legado da crise brasileira e de seus administradores.

Agenda antiga das entidades patronais, de acordo com Perondi (2011), a desregulamentação das relações de trabalho já havia avançado muito durante o governo de Fernando Henrique Cardoso (FHC), quando foram realizadas várias mudanças na legislação trabalhista. Mesmo durante os governos petistas, não houve uma reversão dessa tendência de precarização das condições de trabalho, pois a estratégia então consistia em conciliar os interesses de patrões e empregados.

No entanto, a deterioração econômica resultante da crise e os limites encontrados pelo padrão de reprodução capitalista exportador de produtos primários aumentaram a pressão patronal para uma nova reforma que flexibilizasse ainda mais a relação de trabalho. Esta recebeu impulso importante com o governo Temer e merece ser detalhadamente analisada.

\section{ALTERAÇÕES NA LEGISLAÇÃO TRABALHISTA}

O objetivo principal dessa ofensiva do capital consiste em institucionalizar o barateamento e a precarização do trabalho, que o governo e empresários chamam de modernização das relações trabalhistas. Na prática, além de retirar direitos históricos dos trabalhadores, trata de legalizar e generalizar formas de exploração já utilizadas nos principais setores produtivos no Brasil, como a 
terceirização, trabalho temporário e intermitente, o trabalho análogo à escravidão, entre outros.

O argumento é de que é necessário dar segurança jurídica ao empresariado, quando na verdade buscam reduzir os custos de contratação e demissão, permitindo que os patrões utilizem a força de trabalho quando necessitem e possam descartá-la em seguida sem maiores custos e implicações.

Em primeiro lugar, há que destacar que a legislação trabalhista brasileira, desde que foi criada, serviu como um piso por sinal bastante rebaixado - para regular um mercado de trabalho estruturalmente precarizado e flexível. No entanto, o empresariado não respeita nem esse parâmetro legal, o que pode ser comprovado pelo elevado número de processos e demandas na Justiça do Trabalho.

Talvez, por isso, dizem agora que essa mediação estatal deveria acabar: o Presidente da Câmara de Deputados, Rodrigo Maia, Partido Democratas (DEM-RJ), afirmou taxativamente que a Justiça do Trabalho não deveria existir; já o Presidente do Tribunal Superior do Trabalho (TST), Ives Gandra Martins Filho, afirmou que as decisões da corte que preside são muito parciais em favor do trabalhador, levando a que muitos demandem o patrão sem nenhum motivo, ou mesmo se automutilem para receber indenizações.

Por trás desse discurso se esconde uma estratégia de ataque aos direitos trabalhistas organizada desde distintas frentes do Estado, que envolve personagens-chave dos poderes Executivo, Legislativo e Judiciário. Isso, evidentemente, responde ao clamor de entidades patronais da indústria, agricultura e serviços, que lideram campanhas por mudanças duras na lei trabalhista para baratear a força de trabalho e aumentar a produtividade da economia brasileira. Para a CNI, por exemplo, aumentar a jornada laboral para 12 horas diárias ou até 80 horas semanais é o que aumentará a competitividade. (CNI..., 2016).

Com base no exposto, é possível concluir que a reforma trabalhista aprovada pela Lei $\mathrm{n}^{\circ}$ 13.467, de 1 de julho de 2017, de iniciativa de Temer, (mas que foi bastante ampliada pelos deputados), rebaixa o piso mínimo da legislação trabalhista e o transforma num teto, ou seja, permite que os direitos possam ser reduzidos através da prevalência do negociado sobre o legislado.

No que se refere à negociação individual, o patrão e o trabalhador poderão assinar contratos que permitam a redução de 
custos de demissão, aumentar a jornada diária e diminuir o tempo de intervalo, utilizar banco de horas para não pagar horas extras; até mesmo as pausas para amamentação terão que ser negociadas entre a mãe trabalhadora e o patrão.

A negociação coletiva deixa de ser um instrumento de ampliação de direitos para legalizar a possibilidade de reduzi-los, pois permite estabelecer termos inferiores em 15 pontos da Lei Trabalhista, sobretudo no que se refere à jornada de trabalho e remuneração. Ao mesmo tempo, permite que a representação dos trabalhadores nas negociações com os patrões se realize através de uma comissão de representantes em cuja eleição está vedada a participação do sindicato. Isso aumenta o poder de cooptação desses representantes e implica um duro golpe a organização sindical.

O mais provável é que os trabalhadores negociem os termos de sua própria precarização, permitindo a existência de vários tipos de contratos, inclusive em uma mesma empresa. Cumpre com perfeição a estratégia neoliberal de fragmentar o trabalhador coletivo e eliminar as condições universais que unificam os trabalhadores, que só possuem força enquanto sujeito coletivo; sozinhos são presas fáceis dos interesses patronais.

Outras mudanças importantes que essa Lei propõe são: ampliação do período de trabalho parcial (passa de 25 para 30 horas); libera o trabalho autônomo (garante relação de continuidade e exclusividade entre contratante e autônomo sem configurar vinculo de emprego); facilita e barateia a demissão imotivada; institui o trabalho intermitente ou jornada de zero hora (alterna períodos de trabalho e inatividade onde o trabalhador deve estar à disposição para quando o patrão o chame); institui o teletrabalho (trabalho remoto, realizado em casa); permite que mulheres grávidas possam trabalhar em lugares insalubres (desde que um médico a autorize); acaba com a contribuição sindical obrigatória. (DEPARTAMENTO INTERSINDICAL DE ESTATÍSTICA E ESTUDOS SOCIOECONÔMICOS, 2017).

Outro ataque foi a aprovação da Lei no 13.429 , de 31 de março de 2017, um projeto do governo de FHC de 1998, resgatado pelos deputados e aprovado às pressas, que permite a terceirização da força de trabalho inclusive nas atividades principais de uma empresa. 
A Lei aprovada permite que a empresa que oferece serviço terceirizado (que pode ser composta por uma única pessoa, disfarçando a relação de emprego) pode subcontratar outra empresa para realizar a atividade, abrindo assim a possibilidade para uma quarteirização do trabalho, gerando uma cadeia interminável de subcontratações. Também dificulta que a empresa contratante do serviço seja responsabilizada no caso em que as empresas terceirizadas não cumpram com suas obrigações com os trabalhadores.

Os trabalhadores terceirizados representam 27\% do mercado formal no Brasil e pertencem a uma espécie de segunda classe: recebem salários mais baixos, têm jornadas mais compridas e extenuantes, são vítimas de calotes no final do contrato, não têm as mesmas condições laborais daqueles que são diretamente contratados, sem falar que são as principais vítimas de doenças, acidentes e mortes no local de trabalho. (CENTRAL ÚNICA DOS TRABALHADORES; DEPARTAMENTO INTERSINDICAL DE ESTATÍSTICA E ESTUDOS SOCIOECONÔMICOS, 2014).

Essa Lei também ampliou a possibilidade de utilização do contrato de trabalho temporário de 90 para 180 dias (com possibilidade de extensão para mais 90 , totalizando 9 meses), limite de duração dessa modalidade de contratação que prevê condições inferiores.

Outros dois importantes projetos que alteram direitos dos trabalhadores estão tramitando: um projeto de reforma da previdência social e uma mudança na Lei sobre o trabalho rural.

O governo de FHC realizou uma reforma nas aposentadorias dos trabalhadores da iniciativa privada em 1998. No ano de 2003 o governo Lula completou o serviço alterando a Previdência dos trabalhadores do setor público. Agora o governo de Temer acelera a marcha por uma nova e mais profunda reforma da Previdência, para aumentar a idade mínima e o tempo de contribuição para ter acesso ao direito; na prática, inviabilizando-o para milhões de trabalhadores.

A justificativa do governo Temer, para a reforma, é a existência de um suposto déficit nas contas que, sem a mudança, inviabilizaria o sistema ou faltariam recursos para políticas sociais. O Ministro da Fazenda, Henrique Meirelles, foi outro a usar a chantagem para 
defender a reforma, afirmando que sem ela a economia brasileira não sairia da crise.

Dados da Associação Nacional dos Auditores Fiscais da Receita Federal do Brasil (ANFIP, 2016) desmentem a ambos: as contas da Previdência são superavitárias, ano após ano, inclusive no meio da profunda crise econômica atual. O saldo é positivo apesar de: 1) o governo poder desviar até 30\% dos recursos da Previdência para outros fins, com o mecanismo da Desvinculação das Receitas da União (DRU); 2) vários setores da economia terem sido beneficiados nos últimos anos com isenção de impostos, entre eles a contribuição patronal ao sistema previdenciário; 3) muitas empresas sonegarem essa contribuição obrigatória, fazendo com que as dívidas somadas dos grandes grupos superem o volume de 400 bilhões de reais.

$O$ verdadeiro objetivo da reforma consiste no saqueio da poupança dos trabalhadores por parte do sistema financeiro, além da mercantilização de um direito que passará a ser vendido com os fundos privados de pensão. $\mathrm{O}$ resultado esperado é a redução do valor da força de trabalho, à custa da saúde e da vida do trabalhador.

Tramita no congresso uma proposta de reforma do trabalho rural que prevê que as empresas paguem o trabalhador com salário ou remuneração de qualquer espécie, ou seja, podem pagar o trabalho com moradia e comida. Também permite que a jornada laboral seja ampliada para até 12 horas diárias e que o trabalhador pode estar até 18 dias seguidos trabalhando sem um descanso semanal, por motivos de força maior ou por necessidade de concluir serviços.

O deputado Nilson Leitão (PSDB-MT), que preside a frente parlamentar agropecuária no Congresso, é o autor do projeto, e o justifica pela necessidade de modernizar a legislação laboral e adequá-la aos usos e costumes do campo, com o objetivo de aumentar os lucros e diminuir custos. Modernizar, nesse caso, significa constitucionalizar o costume nunca abandonado de usar força de trabalho em condições de escravidão nas fazendas do agronegócio.

\section{CONCLUSÃO}

Ao longo das seções anteriores, este texto procurou demonstrar como os efeitos da crise econômica mundial afetaram o desempenho do Brasil e reforçaram a ofensiva do capital contra os direitos dos trabalhadores. Também foi destacado como as políticas 
econômicas mantiveram, em geral, a orientação neoliberal ditada pelo capital financeiro.

O país iniciou o ano de 2017 com perspectivas de continuar a grave recessão que enfrentou nos dois anos anteriores, que já são suficientes para configurar a mais longa crise que a economia brasileira já passou, com contração de 3,8\% e 3,6 do PIB em 2015 e 2016, respectivamente. Os sinais de recuperação só existem nas promessas da equipe econômica do governo Temer, devidamente condicionados à realização das reformas e da manutenção da política econômica.

No entanto, Temer faz pouco caso de sua impopularidade ou falta de legitimidade, pois sabe que encabeça um governo que chegou onde está para realizar as tarefas que não passariam pelo crivo do voto popular. A agenda econômica nacional, aliás, aparece cada vez mais desvinculada das urnas, pelo menos desde sua institucionalização com o Plano Real, em 1994.

Dada a profundidade da crise econômica e o caráter instável da política brasileira atual, é possível inclusive que o próprio Temer não consiga terminar o mandato, devido à quantidade de denúncias que o implicam pessoalmente em esquemas de corrupção. Enquanto se discute quem governa, o capital consegue avançar sua ofensiva e ditar a agenda de governo.

Por outro lado, os trabalhadores estão reagindo a essa ofensiva e aumentando a resistência às reformas. O êxito da greve geral chamada pelas centrais sindicais no dia 28 de abril conseguiu frear parcialmente a tramitação das reformas e provocou excisões no bloco dominante. Ainda que insuficiente para barrar a aprovação da reforma trabalhista, parece indicar o caminho possível para barrar a ofensiva do capital e, a partir daí, criar uma política que atenda aos interesses da maioria trabalhadora.

\section{REFERÊNCIAS}

ASSOCIAÇÃO NACIONAL DOS AUDITORES-FISCAIS DA RECEITA FEDERAL DO BRASIL. Análise da Seguridade Social 2015. 16. ed. Brasília, DF, ago. 2016. Disponível em:<https://www.anfip. org.br/doc/publicacoes/20161013104353_Analise-da-SeguridadeSocial-2015_13-10-2016_Anlise-Seguridade-2015.pdf>. Acesso em: 20 fev. 2017. 
BARBOSA, N. Dez anos de política econômica. In: SADER, E. (Org). 10 anos de governos pós-neoliberais no Brasil: Lula e Dilma. São Paulo: Boitempo; Rio de Janeiro: Flacso Brasil, 2013.

BRAGA, R. "O fim do lulismo". In: JINKINGS, DORIA, CLETO (orgs), Por que gritamos golpe? para entender o impeachment e a crise política no Brasil. São Paulo: Boitempo, 2016.

CARNEIRO, M. Empregos na crise oferecem renda menor e sem proteção. Folha de São Paulo, São Paulo, 23 jan. 2017. Disponível em:<http://www1.folha.uol.com.br/mercado/2017/01/1852181empregos-na-crise-oferecem-renda-menor-e-sem-protecao.shtml $>$. Acesso em: 15 mar. 2017.

CENTRAL ÚNICA DOS TRABALHADORES. Secretaria Nacional de Relações de Trabalho; DEPARTAMENTO INTERSINDICAL DE ESTATÍSTICA E ESTUDOS SOCIOECONÔMICOS. Terceirização e desenvolvimento: uma conta que não fecha. São Paulo, 2014. Dossiê acerca do impacto da Terceirização sobre os trabalhadores e propostas para garantir a igualdade de direitos.

CNI defende mudança em leis trabalhistas e cita jornada de 80 horas semanais. O Estado de São Paulo, São Paulo, 8 jul. 2016. Disponível em:<http://economia.estadao.com.br/noticias/geral,cnidefende-mudanca-em-leis-trabalhistas-e-cita-jornada-de-80-horassemanais,10000061772>. Acesso em: 20 fev. 2017.

COGGIOLA, O. Impeachment, crise e golpe: o Brasil no palco da tormenta mundial. Blog Boitempo, São Paulo, 2016. Disponível em:<https://blogdaboitempo.com.br/2016/05/31/impeachment-crisee-golpe-o-brasil-no-palco-da-tormenta-mundial/>. Acesso em: $15 \mathrm{fev}$. 2017.

CONFEDERAÇÃO NACIONAL DA INDÚATRIA. Informe conjuntural. Ano 29, n.03, jul./set.2013. Disponível em:<https://staticcms-si.s3.amazonaws.com/media/filer_public/6c/e0/6ce06d16-49da4930-9aef-064a1f1c7b22/20130925102210567724e.pdf>. Acesso em: 15 feb. 2017.

DEPARTAMENTO INTERSINDICAL DE ESTATÍSTICA E ESTUDOS SOCIOECONÔMICOS. Balanço das negociações dos reajustes salariais do $1^{\circ}$ semestre de 2016. Estudos e Pesquisas, São Paulo, n. 81, set. 2016.

A reforma trabalhista e o impacto para as relações de trabalho no Brasil. Nota técnica São Paulo, n. 178, maio 2017. 
DIRCEU, J. O papel do PT e da oposição no Brasil. Revista Interesse Nacional, São Paulo, n. 14, 2011.

FATTORELLI, M. L. O ajuste fiscal alimenta o corrupto sistema da dívida. Blog Marxismo 21, 2015. Dossiê Ajuste Fiscal. Disponível em:< http://marxismo21.org/ajuste-fiscal/>. Acesso em: 23 fev. 2017.

FERNANDES, F. A revolução burguesa no Brasil. Rio de Janeiro: Zahar Editores, 1987.

FERNANDES, M. Dilma caiu por não apoiar 'Ponte para o Futuro', diz Temer. Revista Exame, São Paulo, 23 set. 2016. Disponível em: $<$ http:// exame.abril.com.br/brasil/dilma-caiu-por-nao-apoiar-ponte-para-ofuturo-diz-temer/>. Acesso em: 20 fev. 2017.

FUNDAÇÃO CENTRO DE EESTUDOS COMÉRCIO EXTERIOR. Informativo Balança comercial, ano 2, n. 9, jan. 2012. Disponível em: $<$ http://www.funcex.org.br/publicacoes/boletins/pdf/Inf_ Janeiro2012.pdf $>$. Acesso em: 15 feb. 2017.

GASTO com seguro-desemprego cai apesar de maior número de desempregados. Portal G1, São Paulo, nov. 2015. Disponivel:<http:// g1.globo.com/bom-dia-brasil/noticia/2015/11/gasto-com-segurodesemprego-cai-apesar-do-aumento-nas-demissoes.html>. Acesso em: 15 fev. 2017.

HARVEY, D. O enigma do capital e as crises do capitalismo. São Paulo: Boitempo, 2011.

INSTITUTO BRASILEIRO DE GEOGRAFIA E ESTATÍSTICA. Pesquisa Nacional por Amostra de Domicílios Contínua - segundo trimestre de 2017: indicadores IBGE. Rio de Janeiro, 2017. Disponível em:<http://www.ibge.gov.br/home/estatistica/indicadores/ trabalhoerendimento/pnad_continua/>. Acesso em: 20 mar. 2017

MARINI, R. M. Dialectica de la dependência. México: Ediciones Era, 1981.

MARTINS, J. Breaking Bad (Temp. 2 Ep. 3) Desenvolvimento desigual e combinado do capital em tempo real. Boletim Crítica Semanal da Economia, São Paulo, ano 31, n. 1323, jan. 2017. Disponível em:<http://criticadaeconomia.com.br/breaking-bad-temp-2-ep-3desenvolvimento-desigual-e-combinado-do-capital-em-tempo-real/>. Acesso em: 20 fev. 2017.

MOREIRA, A. Em Davos, 'Brasil pela metade do preço' atrai interesse de investidor. Valor Econômico, São Paulo, 25 jan. 2016. Disponível em:<http://www.valor.com.br/brasil/4408074/em-davos-brasil-pela- 
metade-do-preco-atrai-interesse-de-investidor>. Acesso em: 20 fev. 2017.

OSORIO, J. Teoría marxista de la dependencia: história, fundamentos, debates y contribuciones. México: UAM-X, Ítaca, 2016.

PERONDI, E. Conciliação e precarização: a política trabalhista do governo Lula (2003-2010). Florianópolis: Em Debate, 2011. Disponível em: $<$ https://issuu.com/editoriaemdebate/docs/perondieduardo $>$. Acesso em: 20 fev. 2017.

SADER, E. Crisisbrasileña era estrategia golpista. La Jornada, México, 13 maio 2016. Opinión. Disponível em: <http://www.jornada.unam. mx/2016/05/13/opinion/023a1mun>. Acesso em: 20 fev 2017.

SINGER, A. Cutucando onças com varas curtas: o ensaio desenvolvimentista no primeiro mandato de Dilma Rousseff (20112014). Novos Estudos Cebrap, São Paulo, n. 102, p. 39-67, jul. 2015.

SOTELO VALENCIA, Adrián. México (re) cargado: dependencia, neoliberalismo y crisis. México: UNAM, Ítaca, 2014.

VALENTE, R. Em diálogos gravados, Jucá fala em pacto para deter avanço da Lava Jato. Folha de São Paulo, São Paulo, 23 maio 2016. Disponível em:<http://www1.folha.uol.com.br/ poder/2016/05/1774018-em-dialogos-gravados-juca-fala-em-pactopara-deter-avanco-da-lava-jato.shtml>. Acesso em: 20 fev. 2017.

WIZIAK, J. Metade dos principais grupos do país vende ativos para pagar a dívida. Folha de São Paulo, São Paulo, 5 set. 2016. Disponível em:<http://www1.folha.uol.com.br/mercado/2016/09/1810259metade-dos-principais-grupos-do-pais-vende-ativos-para-pagardivida.shtml>. Acesso em: 20 fev. 2017.

\section{Nota}

1 O conceito de padrão de reprodução do capital se refere às formas históricas que assume a reprodução do capital em determinados países, os eixos ou atividades principais aos quais está orientada a produção e também a circulação e distribuição de bens. Nas economias dependentes vigorou o padrão de reprodução de industrialização substitutiva de importações entre os anos 1940 e 1970-80, que foi substituído na atual fase neoliberal por um padrão baseado em exportações. Para o Brasil, isso implicou uma reprimarização profunda da economia. Sobre o conceito de padrão de reprodução do capital na América Latina, ver Sotelo Valencia (2014) e Osorio (2016). 
